\title{
A EDUCAÇÃO PROFISSIONAL E TECNOLÓGICA COMO ESPAÇO SOCIO- OCUPACIONAL DO ASSISTENTE SOCIAL: DESAFIOS E POSSIBILIDADES PARA ATUAÇÃO DO ASSISTENTE SOCIAL NO IFMG
}

\author{
Natalia Aparecida Dornelas Miranda ${ }^{1}$ \\ Pablo Menezes e Oliveira ${ }^{2}$ \\ DOI: https://doi.org/10.36524/profept.v5i3.1246
}

\begin{abstract}
RESUMO
O presente artigo tem como objetivo abordar a educação profissional e tecnológica enquanto um espaço sócio - ocupacional do assistente social. Para isso, foi desenvolvida uma pesquisa no âmbito do Instituto Federal de Educação, Ciência e Tecnologia de Minas Gerais - IFMG, que contou com a participação de 13 assistentes sociais que atualmente trabalham nesta instituição. Integrando uma pesquisa em desenvolvimento, em nível de mestrado em Educação Profissional e Tecnológica, este estudo revelou, através de abordagens metodológicas qualitativa e quantitativa, os principais desafios e possibilidades para atuação dos assistentes sociais no IFMG, considerando os impactos provocados pela política neoliberal que provoca a retração do Estado no que se refere ao investimento em políticas públicas.
\end{abstract}

Palavras-chave: assistência estudantil; IFMG; assistente social.

\author{
PROFESSIONAL AND TECHNOLOGICAL EDUCATION AS A SOCIAL- \\ OCCUPATIONAL SPACE FOR THE SOCIAL WORKER: CHALLENGES AND \\ POSSIBILITIES FOR THE PERFORMANCE OF THE SOCIAL WORKER AT IFMG
}

\begin{abstract}
This article aims to address professional and technological education as a socio-occupational space for the social worker. For this, a survey was developed within the scope of the Federal Institute of Education, Science and Technology of Minas Gerais - IFMG, which included the participation of 13 social workers who currently work at this institution. Integrating research in development, at the Master's level in Professional and Technological Education This study revealed, through qualitative and quantitative methodological approaches, the main challenges and possibilities for the work of social workers at the IFMG, considering the impacts caused by the neoliberal politics that causes the retraction of the State with regard to investment in public politics.
\end{abstract}

Keywords: student assistance; IFMG; social worker.

\footnotetext{
${ }^{1}$ Instituto Federal de Educação Ciência e Tecnologia de Minas Gerais. E-mail: natalia.miranda@ifmg.edu.br

${ }^{2}$ Instituto Federal de Educação Ciência e Tecnologia de Minas Gerais. E-mail: pablo.menezes@ifmg.edu.br
} 


\section{INTRODUÇÃO:}

Neste artigo são apresentados os resultados de uma pesquisa realizada com os assistentes sociais que atuam nos campi do Instituto Federal de Educação Ciência e Tecnologia de Minas Gerais - IFMG. O trabalho em tela está vinculado ao projeto de pesquisa "Acompanhamento educacional e sócio familiar no Instituto Federal de Educação Ciência e Tecnologia de Minas Gerais: concepções e propostas no âmbito da assistência estudantil," desenvolvido no Programa de Pós- Graduação em Educação Profissional e Tecnológica (PROFEPT).

O IFMG, instituição pública de ensino que compõe a Rede Federal de Educação Profissional e Tecnológica é constituído, atualmente, por 18 campi e uma Reitoria situados nas seguintes cidades, respectivamente: Arcos; Bambuí; Betim; Congonhas; Conselheiro Lafaiete; Formiga; Governador Valadares; Ibirité; Ipatinga; Itabirito; Ouro Branco; Ouro Preto; Piumhi; Ponte Nova; Ribeirão das Neves; Sabará; Santa Luzia; São João Evangelista e Belo Horizonte. Cumpre ressaltar que, dos 18 campi, apenas 04 não possuem, em seu quadro de profissionais, assistente social. São eles: Arcos, Itabirito, Piumhi e Ibirité. Atualmente, a instituição conta com 15 assistentes sociais distribuídos nos demais campi e na Reitoria, considerando-se que nesta unidade encontra-se a Diretoria de Assuntos estudantis, criada no ano de 2019. Desses, 14 participaram da pesquisa em questão através do preenchimento de um questionário disponibilizado no google formas.

A temática abordada foi construída tendo um dos autores deste material na condição de assistente social no IFMG, especificamente no campus situado em Ouro Preto - MG. Portanto, nos dados obtidos através do questionário aplicado, representados pelos gráficos e quadros aqui registrados, não são abarcadas informações pertinentes ao campus Ouro Preto. Porém, no discorrer da análise, as vivências desta profissional são consideradas.

\section{PERCURSO METODOLÓGICO:}

A pesquisa desenvolvida utilizou as abordagens qualitativa e quantitativa, pois além dos dados obtidos através dos questionários aplicados, também foram realizados levantamentos documental e bibliográfico. Nesse sentido, a interação entre as técnicas mencionadas foi essencial para a análise dos dados. Conforme destaca Minayo (2004, p. 22) “o conjunto de 
dados quantitativos e qualitativos, porém, não se opõem. Ao contrário, se complementam, pois a realidade abrangida por eles interage dinamicamente, excluindo qualquer dicotomia".

Os dados obtidos nesta pesquisa revelam informações sobre a atuação dos assistentes sociais nos campi do IFMG. Como tem se desenvolvido o trabalho destes profissionais nesta instituição de ensino, quais suas contribuições e os desafios encontrados. Portanto, trata-se de uma análise que considera as características e requisições apresentadas pelos elementos que constituem este espaço sócio ocupacional, são eles: a instituição, o profissional e o público alvo atendido através das ações desenvolvidas.

\section{RESULTADOS E DISCUSSÃO:}

As abordagens teóricas sobre a Educação Profissional e Tecnológica (EPT), no território brasileiro, indicam o ano de 1909 como o marco inicial da educação profissional na rede federal de ensino através da implementação da Escola de Aprendizes Artífices. Desde então, a cada contexto histórico marcado por suas particularidades econômicas, culturais, sociais e políticas, o ensino profissional brasileiro apresenta novas configurações e denominações. Os Institutos Federais de Educação Ciência e Tecnologia, na rede federal de ensino, surgiram a partir da lei 11.892 de 29 de dezembro de 2008. Portanto, foram 99 anos de história da educação profissional até se estabelecer os Institutos Federais. (GARCIA, 2018, P.12)

Nestes longos anos de história, existem registros de um caminho percorrido pela EPT constituído por várias características influenciadas pelos cenários locais, regionais e nacional. O IFMG surge em 2008 a partir da aglutinação dos CEFET Ouro Preto, CEFET Bambuí, da Escola Agrotécnica Federal de São João Evangelista e das Unidades Descentralizadas (UNEDs) Congonhas e Formiga (IFMG, 2021). Cria-se uma nova instituição, constituída, atualmente, por 18 campi e a reitoria, que propõe a oferta de educação superior, básica e profissional de forma pluricurricular e multicampi. especializada para disponibilizar educação profissional e tecnológica ofertando diversas modalidades de ensino. (PACHECO, 2015)

Quando o IFMG foi implementado, faziam parte do corpo técnico 04 assistentes sociais, vinculadas às seguintes instituições preexistentes: CEFET Ouro Preto, UNED Congonhas e Escola Agrotécnica de Bambuí. Em 2010 foi realizado o primeiro concurso público com a oferta de 01 vaga para assistente social, para atender o campus São João Evangelista. Porém, foi convocada mais uma profissional para o campus Governador Valadares. Até o ano de 2021, 
foram realizados mais 02 concursos, um em 2014 e o outro em 2016. Atualmente, 15 assistentes sociais estão vinculados a esta instituição. Esses profissionais compõem o Núcleo de Assistentes Sociais do IFMG (NASIFMG) criado através da Portaria $n^{\circ} 716$ de 07 de outubro de 2010. Este coletivo foi organizado com a finalidade de promover a "articulação dos Assistentes Sociais do Instituto, e tem como proposta o fortalecimento da categoria visando à melhoria do fazer profissional em consonância com o Projeto Ético-Político do Serviço Social.” (IFMG, 2010). Considerando o histórico de presença de assistentes sociais no IFMG foi construído o gráfico 1.

Gráfico 1: Tempo de atuação como assistente social do IFMG

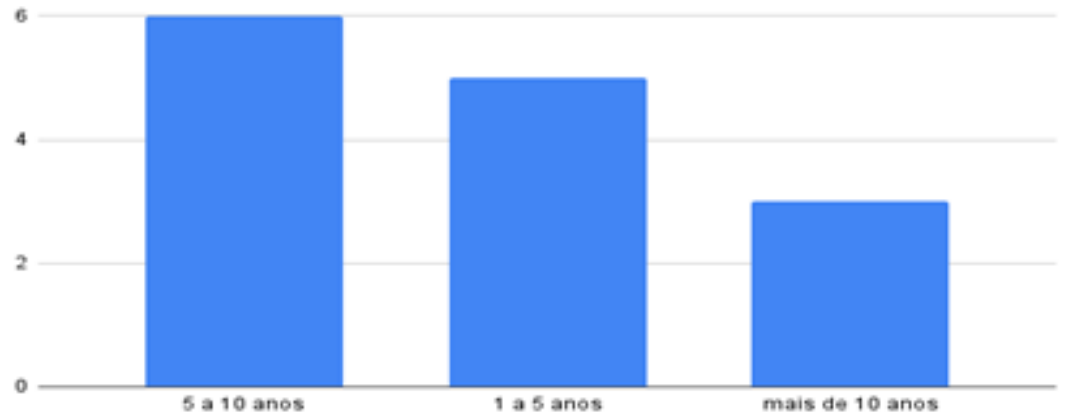

Fonte: dados da pesquisa, 2021

O gráfico 1 demonstra há quanto tempo os assistentes sociais que participaram da pesquisa atuam no IFMG. É perceptível um aumento da presença deste profissional a partir da ampliação e expansão da instituição e da implementação do Programa Nacional de Assistência Estudantil (PNAES). O PNAES foi instituído pelo decreto $\mathrm{n}^{\circ}$ 7.243, de 19 de julho de 2010 e estabelece em seu artigo $1^{\circ}$ que "O Programa Nacional de Assistência Estudantil - PNAES, executado no âmbito do Ministério da Educação, tem como finalidade ampliar as condições de permanência dos jovens na educação superior pública federal" e aponta, em seu artigo $4^{\circ}$, que os Institutos Federais, apesar de não ofertarem apenas curso superior, também são abrangidos por esta legislação

[...] as ações de assistência estudantil serão executadas por instituições federais de ensino superior, abrangendo os Institutos Federais de Educação, Ciência e Tecnologia, considerando suas especificidades, as áreas estratégicas de ensino, pesquisa e extensão e aquelas que atendam às necessidades identificadas por seu corpo discente. (BRASIL, 2010) 
A partir de então, a assistência estudantil, tanto na esfera das Universidades Federais como nos Institutos Federais, encontra-se na condição de política pública em todo território nacional. Esta regulamentação garante à assistência estudantil fonte orçamentária própria e orientações sobre as ações pertinentes a esta política. Normatizações como esta são imprescindíveis para assegurar o direito à educação, que não deve ser restrito à garantia de acesso, mas também à permanência até a conclusão do curso. De modo que sejam desenvolvidas ações para atender as diversas demandas dos estudantes, ofertando condições para que eles possam superar possíveis obstáculos e desafios em sua trajetória na instituição de ensino.

O assistente social é um dos profissionais convocados para atuar na implementação do Programa Nacional de Assistência Estudantil. Historicamente, assumiu um protagonismo no planejamento e execução das ações vinculadas ao PNAES. No âmbito do IFMG, o assistente social é requisitado, principalmente, para atuar na execução dos programas de auxílios socioeconômicos. Segundo Garcia (2019, p. 88),

[...] a inserção dos assistentes sociais nos IFTs ocorreu, em sua maioria, a partir de 2008, no período de discussão (e posterior aprovação) do PNAES por meio do Decreto n.7.234/2010. Período que foi permeado por expansão dos IFETs e pela aprovação do Programa de Apoio a Planos de Reestruturação e Expansão das Universidades Federais (Reuni) que visou a ampliação das condições de acesso e permanência na educação superior.

Todavia, é necessário desconstruir compreensões equivocadas que corroboram para que o desenvolvimento das atividades vinculadas ao PNAES sejam atribuídas exclusivamente ao assistente social. O trabalho coletivo e articulado entre os diversos profissionais da educação é fundamental para que o PNAES seja compreendido como um direito social e favoreça o rompimento com as concepções, historicamente construídas, que caracterizam as intervenções promovidas no âmbito da assistência estudantil como ações assistencialistas e como concessões do Estado.

Sobre a formação dos assistentes sociais do IFMG, 58\% concluíram a graduação a partir de 2008, ano de criação dos Institutos Federais de Educação Ciência e Tecnologia. Todos cursaram pós-graduação, em sua maioria lato sensu, conforme demonstra o gráfico 2. 


\section{Gráfico 2: pós graduação dos assistentes sociais do IFMG}

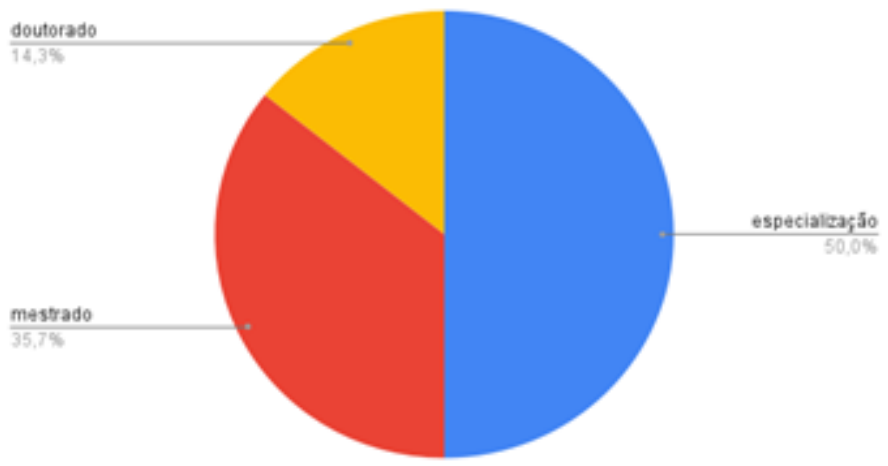

Fonte: dados da pesquisa, 2021.

Para além do estímulo provocado pelo incentivo à qualificação previsto no Plano de Carreira dos Cargos Técnico-Administrativos em Educação, no âmbito das Instituições Federais de Ensino vinculadas ao Ministério da Educação (BRASIL, 2005), os dados apontados remetem à importância de refletir e reconhecer a formação continuada como uma ação constante e imprescindível ao exercício profissional do assistente social. É fundamental uma formação continuada que contribua para a efetivação da dimensão teórico-prática, para a apropriação das tecnologias disponíveis, para qualificar a produção de documentos e para organizar informações pertinentes à realidade social que se expressam no cotidiano profissional. Segundo Cartaxo,

é pertinente pensar a formação continuada do assistente social na perspectiva do método histórico-dialético, tendo como suporte a categoria da práxis. E, além disso, discutir a necessidade de formação crítica dos assistentes sociais, de modo a qualificar sua prática profissional na direção do compromisso com a classe trabalhadora, na construção de uma sociedade sem desigualdade social. (CARTAXO, p. 244)

O código de ética profissional dos assistentes sociais estabelece como um de seus princípios fundamentais o "compromisso com a qualidade dos serviços prestados à população e com o aprimoramento intelectual, na perspectiva da competência profissional” (CFESS, 2012). Portanto, trata-se de uma orientação que pressupõe a importância e necessidade da procura constante pela qualificação. Essa deve proporcionar ao assistente social uma formação ao longo da vida profissional nas dimensões teórica, técnica e política, que extrapolem as exigências impostas pelo mercado e que provoquem reflexões sobre a própria prática. 
No que diz respeito à carga horária de trabalho, os editais dos concursos para assistente social do IFMG preveem 40 horas semanais. 64\% dos assistentes sociais do IFMG cumprem esta carga horária semanal de trabalho. Os demais afirmaram cumprir 30h, uma vez que aderiram à flexibilização da jornada de trabalho prevista na resolução $\mathrm{n}^{\circ} 35$ de 29 de outubro de 2020, que dispõe sobre a regulamentação da jornada de trabalho e registro de frequência dos servidores técnicos administrativos em educação (TAEs) do Instituto Federal de Educação, Ciência e Tecnologia de Minas Gerais - IFMG.

Esta flexibilização da jornada de trabalho não é uma possibilidade para todos os TAEs, inclusive os assistentes sociais. Pois, cumprir todas as condicionalidades para aderir ao proposto nesta resolução não é acessível a todos os campi, principalmente para os que possuem um número reduzido de TAEs. Isso inviabiliza cumprir o estabelecido no art. $2^{\circ}$ desta resolução: “A permanência da flexibilização está condicionada ao quantitativo suficiente de servidores que viabilizem o atendimento ininterrupto no período de, pelo menos, 12 (doze) horas." (IFMG, 2019)

Outro motivo do não cumprimento da jornada flexibilizada, refere-se a ocupar cargo de coordenação. Foi possível identificar apenas duas profissionais nesta situação. Além de exercer as competências e atribuições privativas do assistente social, o profissional também coordena o setor responsável por todas as ações vinculadas à assistência estudantil.

Importante destacar que o IFMG assim como outros espaços sócio-ocupacionais, existentes no âmbito das esferas municipais, estaduais, federais e privadas, não cumpre a Lei n. 12.317 de 27 de agosto de 2010, que estabeleceu a jornada de trabalho de 30 horas semanais para assistentes sociais, sem redução salarial. Esta importante conquista da categoria profissional tem como objetivo garantir melhores condições de trabalho para os assistentes sociais e consequentemente mais qualidade no atendimento ao público. No entanto, esta lei foi questionada e desrespeitada pelo próprio governo federal que

através do Ministério do Planejamento, Orçamento e Gestão, expediu uma orientação normativa para o não cumprimento da lei das 30 horas, pois, equivocadamente, normatiza que para reduzir a jornada de trabalho, os/as assistentes sociais deverão optar pela redução salarial - prova inequívoca do desrespeito à lei. (CFESS, 2011).

Inseridos na jornada de trabalho, majoritariamente de 40 horas semanais, estruturada de acordo com a realidade pertinente a cada campus, os assistentes sociais afirmaram desenvolver diversas ações. Além de executarem as atribuições privativas e competências profissionais, 
conforme estabelecido na lei $\mathrm{n}^{\circ} 8.662$ de 1993, que dispõe sobre a profissão de assistente social, os profissionais demonstraram atuar em ações transversais consideradas importantes para a execução da assistência estudantil.

Em uma das questões do questionário aplicado, foram sugeridas prováveis ações desenvolvidas pelos assistentes sociais inseridos no IFMG e de acordo com as respostas obtidas foi possível verificar que $100 \%$ dos assistentes sociais realizam as seguintes atividades no seu cotidiano institucional: análise socioeconômica para concessão de auxílios socioeconômicos, previstos na política de assistência estudantil do IFMG; atendimentos às demandas espontâneas apresentadas por estudantes que recebem auxílios socioeconômicos; atendimentos em conjunto com outros profissionais do IFMG e encaminhamentos para outras políticas públicas e rede de proteção social. Já $71 \%$ dos profissionais afirmaram que são responsáveis pelos trâmites relacionados aos pagamentos dos auxílios de caráter socioeconômicos, vinculados à assistência estudantil. Isso significa que executam função administrativa, como organizar a planilha de pagamento dos auxílios e encaminhar ao setor financeiro responsável por efetuar o repasse dos auxílios aos alunos que tiveram os auxílios permanência deferidos ${ }^{3}$. Os $57 \%$ dos assistentes sociais entrevistados realizam o controle de frequência dos estudantes inseridos em programas de caráter socioeconômicos de assistência estudantil. Essa ação está vinculada ao acompanhamento relacionado ao cumprimento de uma das condicionalidades estabelecida na Política de Assistência Estudantil do IFMG.

Art.45 Para a permanência nos benefícios ofertados nos programas existentes na Política de Assistência Estudantil do IFMG, os estudantes deverão atender a seguinte condicionalidade: 1 . apresentar frequência mínima de $75 \%$ por disciplina, apurada trimestralmente nos cursos superiores/subsequente ou concomitante e nos cursos técnicos integrados; $\$ 1^{\circ} \mathrm{A}$ ausência de mais de $25 \%$, por disciplina, apurada trimestralmente, poderá ser justificada pelo SEI/IFMG - estudante, em formulário padrão, à Coordenação de Assistência Estudantil ou equivalente, para avaliação do Serviço Social do campus. $\$ 2^{\circ}$

\footnotetext{
${ }^{3}$ Art. 29. O Programa de Bolsa Permanência consiste em auxílio financeiro que tem por finalidade minimizar as desigualdades sociais e contribuir para a permanência dos estudantes no IFMG, possibilitando a integralização do curso. O programa dispõe de quatro modalidades de bolsa: 1. Bolsa Permanência 01 2. Bolsa Permanência 02 SEI/IFMG - $0591523 \quad$ - $\quad$ Resolução do $\quad$ Conselho Superior https://sei.ifmg.edu.br/sei/controlador.php?acao=documento_imprimir_.. 7 off 18 06/07/2020 20:57 3. Bolsa Permanência 034 . Bolsa Permanência $04 \S 1^{\circ}$. Os valores das Bolsas Permanência serão escalonados de modo a atender diferentes perfis de vulnerabilidade social e seus valores serão definidos em Instrução Normativa publicada pela PROEN. §2 ${ }^{\circ}$ Para a concessão das bolsas aos estudantes contemplados, deve-se levar em consideração a estrutura que cada campus/município disponibiliza para o apoio a permanência do estudante, tais como: moradia, alimentação, transporte, além das particularidades referentes ao Índice de Desenvolvimento Humano (IDH) e o custo de vida de cada região no qual o campus está localizado.
} 
Nos campi que não houver assistente social, a Coordenação de Assistência Estudantil ou equivalente, deverá encaminhar o formulário de solicitação à Diretoria de Assuntos Estudantis para parecer. $§ 3^{\circ}$ A ausência de mais de $25 \%$, por disciplina, apurada trimestralmente, sem justificativa, poderá incidir na suspensão ou cancelamento do auxílio.

Estas informações ratificam o envolvimento e protagonismo, historicamente construído, do assistente social na execução de ações vinculadas aos auxílios de caráter socioeconômicos previstos na esfera da assistência estudantil. Nesta direção, 86\% dos profissionais afirmaram que participam do planejamento orçamentário para as ações de assistência estudantil, mostrando que são consultados sobre dados relacionados aos números e tipos de auxílios deferidos, e a existência de demanda reprimida, ou seja, realizam um levantamento de aspectos importantes para definir questões relacionadas aos auxílios socioeconômicos da assistência estudantil. Ocorre que, todo o empenho profissional para viabilizar o acesso dos alunos aos auxílios de caráter socioeconômico, reconhecido como um direito humano e fundamental à educação tem sofrido os rebatimentos das retrações orçamentárias provocadas pelos governos de orientação neoliberal.

Em 2015, o orçamento do Ministério da Educação (MEC) perdeu R \$ 10 bilhões e a verba destinada aos Institutos Federais levou a primeira mordida. Em 2016, o corte de gastos seguiu, tirando R\$ 6,4 bilhões. Depois do impeachment de Dilma (PT) consumado, o governo de Michel Temer (PMDB) apertou mais. Primeiro, no final do ano, com a aprovação da Emenda Constitucional n.95, que congela os gastos públicos no mesmo orçamento por 20 anos. Depois, em fevereiro de 2017, com a portaria n.282, que contingencia despesas já aprovadas na Lei Orçamentária Anual (LOA), em 38 setores. Em 2017, os cortes foram de 4,3 bilhões somados a mais de dois bilhões em 2018. Em um período de quatro anos, a perda foi de mais de 22,7 bilhões em recursos federais para o setor, ou seja, o corte corresponde a $28,15 \%$ sobre os recursos destinados em 2014. (GARCIA, 2019, p. 93)

Em 2021 é possível identificar a continuidade da redução do orçamento destinado aos Institutos Federais. Desta maneira, o cenário orçamentário atual do IFMG equivale ao praticado em 2010. O contexto institucional é de um aumento significativo das demandas, devido a ampliação do número de alunos e de cursos, nestes 12 anos de história e de retração orçamentária, que ameaça a continuidade de todas as ações desenvolvidas pelo IFMG. (IFMG, 2021.b).

Ao abordar aspectos relacionados a expansão, dilemas e desafios da atuação dos assistentes sociais nos Institutos Federais de Educação Ciência e Tecnologia, Garcia (2019, p. 
102) destaca que o assistente social sente-se e é responsabilizado institucionalmente pela execução das ações de assistência estudantil, principalmente no que se refere aos auxílios de caráter socioeconômicos. Isso provoca o entendimento, por parte de servidores alocados em diversos setores, que o assistente social é o profissional responsável por ações relacionadas a análise de renda. Isso revela uma confusão na compreensão das diferenças existentes entre análise socioeconômica e análise de renda. Nesta direção foi possível verificar que $64 \%$ dos assistentes sociais participam do processo de análise de renda, uma das etapas prevista no processo seletivo dos estudantes ingressante através da política de cotas ${ }^{4}$. É importante ressaltar que esta análise de renda é puramente a realização do cálculo da renda familiar per capta dos candidatos a uma vaga para ingressar no IFMG. Isso faz com que qualquer servidor possa executar esta tarefa. Já a análise socioeconômica realizada nos processos seletivos para os auxílios socioeconômicos vinculados à assistência estudantil, trata-se de uma competência do assistente social. "As competências permitem ao profissional realizar a análise crítica da realidade e construir as estratégias necessárias para responder as demandas sociais que estão normatizadas na lei de regulamentação da profissão (8.662/1993).” (CFESS, 2014, p.28).

A implementação e execução do PNAES, nas instituições federais de ensino, sem dúvida, influenciou a expansão deste espaço sócio-ocupacional em que os assistentes sociais se encontram lotados. Porém, a atuação deste profissional não se restringe a estas ações. Faz-se necessário superar esta compreensão reducionista e limitada sobre a atuação do assistente social e reconhece-lo(a) enquanto um(a) profissional que

pode contribuir na compreensão da educação como política social em sua totalidade e que vai além da sala de aula. O trabalho articulado com docentes, técnicos, famílias, estudantes e comunidade externa tem o potencial de superar a fragmentação e o entendimento da assistência estudantil focada na transferência de renda. Além disso, possibilita a expansão das lutas sociais para além desta pauta, ampliando-a para a qualidade da educação e para a luta geral dos trabalhadores dentro desse contexto inóspito de regressão de direitos (GARCIA, 2019. p. 101).

Os assistentes estudantis do IFMG apontaram, ao longo da entrevista, outras ações que fazem parte de seu cotidiano, como atendimentos às demandas espontâneas apresentadas por estudantes que não recebem auxílios socioeconômicos; encaminhamentos para setores internos; acompanhamento periódico dos estudantes inseridos em programas de caráter socioeconômicos

\footnotetext{
${ }^{4}$ Lei no 12.711 de 29 de agosto de 2012. Dispõe sobre o ingresso nas universidades federais e nas instituições federais de ensino técnico de nível médio e dá outras providências.
} 
da política de assistência estudantil; participação nas reuniões dos conselhos de classe e em comissões diversas, apontadas por $93 \%$ dos assistentes sociais. Esta informação demonstra que apesar da ênfase, historicamente estabelecida, nas ações diretamente relacionadas aos auxílios socioeconômicos, os assistentes sociais do IFMG têm realizado intervenções e ocupado espaços que ultrapassam as especificidades dos auxílios de caráter socioeconômico.

As iniciativas na perspectiva de contribuir com a ampliação e o reconhecimento da atuação dos assistentes sociais na política de educação ficam evidentes ao constatar que, além das ações citadas anteriormente, $64 \%$ dos assistentes sociais declararam que compõem o Núcleo de Atendimento à Pessoa com Necessidades Especiais e Específicas (NAPNEE). ${ }^{5}$ Já $71 \%$ estão envolvidos em ações de mobilização dos estudantes e 36\% desenvolvem e/ou participam de projetos de extensão. Conforme destaca Abreu (2009, p. 603), o desenvolvimento de práticas educativas desempenhadas nos processos de mobilização social e organização devem ter como pilares o posicionamento crítico e o compromisso político.

Neste sentido, a atuação profissional em espaços democráticos deve ser reconhecida como estratégia para fomentar a participação dos estudantes e demais trabalhadores da educação nos processos fundamentais para a democratização da gestão e decisões no âmbito da educação escolar. Portanto, a mobilização social como prática educativa do assistente social "direciona-se para o fortalecimento dos espaços de luta de classes, onde é possível gerar e socializar conhecimentos, constituindo sujeitos coletivos capazes de participar da construção da hegemonia das referidas classes subalternas." (CARDOSO,1995 apud ABREU 2009, p.603).

A partir desta postura e compromisso profissional, em ocupar diversos espaços, o assistente social assume o compromisso de propagar para toda comunidade acadêmica, a amplitude inerente às atribuições do assistente social e das ações de assistência estudantil. Esta é uma forma de contribuir para o processo de desconstrução das percepções equivocadas e restritas relacionadas a esta política.

\footnotetext{
5 O Núcleo de Atendimento às Pessoas com Necessidades Educacionais Específicas, NAPNEE, do Instituto Federal de Educação, Ciência e Tecnologia de Minas Gerais, criado por portaria instituída em cada campus, é um Núcleo de assessoramento que articula as ações de inclusão, acessibilidade e o atendimento educacional especializado.

O NAPNEE tem por missão promover a convivência, o respeito à diferença e, principalmente, buscar a quebra de barreiras arquitetônicas, educacionais, comunicacionais e atitudinais na instituição e no espaço social mais amplo, de forma a efetivar os princípios da educação inclusiva. (IFMG, 2021. d)
} 
Portanto, garantir a execução da assistência estudantil vai além da concessão de auxílios socioeconômicos. É imprescindível o envolvimento com os técnicos administrativos vinculados aos diversos setores; docentes, que são profissionais que possuem contato direto e diário com os alunos; diversas políticas sociais setoriais, necessárias para os encaminhamentos a partir das demandas apresentadas pelos alunos e seu grupo familiar. Esta articulação é fundamental para uma compreensão integral do aluno e indispensável para viabilizar o acesso a seus direitos. Dessa forma, o trabalho do assistente social, conforme estabelecido no documento que dispõe sobre os subsídios para atuação dos assistentes sociais na política e educação,

não se restringe ao segmento estudantil e nem às abordagens individuais. Envolve também ações junto às famílias, aos professores e professoras, aos demais trabalhadores e trabalhadoras da educação, aos gestores e gestoras dos estabelecimentos públicos e privados, aos/às profissionais e às redes que compõem as demais políticas sociais, às instâncias de controle social e aos movimentos sociais, ou seja, ações não só de caráter individual, mas também coletivo, administrativo-organizacional, de investigação, de articulação, de formação e capacitação profissional. (CFESS, 2014, p.38)

Para executar cotidianamente as ações mencionadas anteriormente, os assistentes sociais dispõem de alguns instrumentais e técnicas. O gráfico abaixo indica aqueles utilizados pelos assistentes sociais do IFMG.

\section{Gráfico 3: representa as ações executadas pelos assistentes sociais do IFMG}

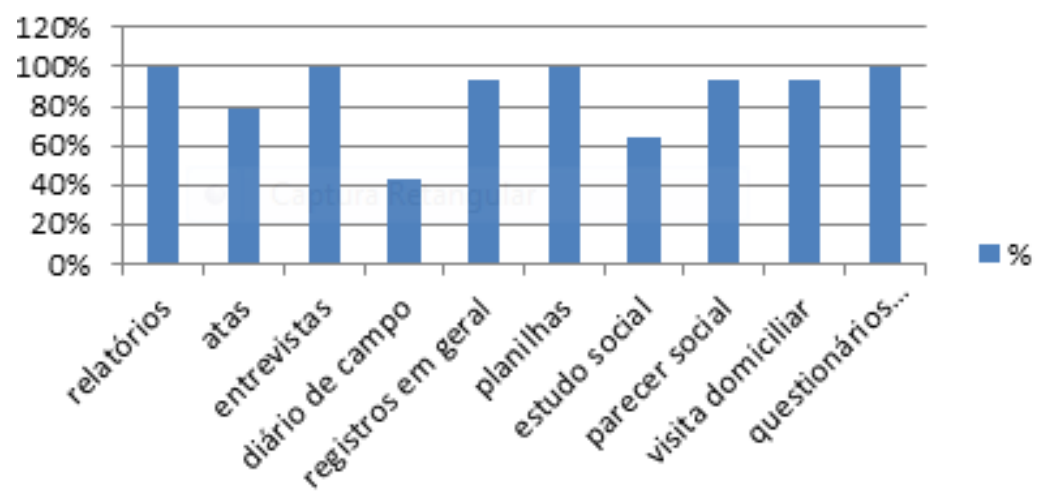

Fonte: dados da pesquisa, 2021.

Abordar as ações profissionais, que estão atreladas às atribuições e competências do assistente social, exige compreender por qual meio essas são executadas, ou seja, quais os 
instrumentais e técnicas utilizadas para dar materialidade às intervenções propostas. A apropriação das técnicas e instrumentos permite ao assistente social operacionalizar sua prática profissional. Por estar no campo da resolutividade das situações postas, é atribuída à dimensão técnica operativa do Serviço Social dar visibilidade à profissão. No entanto, é imprescindível que esta dimensão esteja articulada às dimensões teórico-metodológica e ético política, na perspectiva de garantir ao profissional uma compreensão crítica da realidade. Respaldado em fundamentos teóricos, o assistente social desenvolve a capacidade de perceber e entender os limites e possibilidades impostos a sua atuação profissional como algo relacionado às particularidades do modelo de sociedade vigente e "não como algo interno ou inerente ao próprio exercício profissional, mas como parte do movimento contraditório da própria realidade social." (GUERRA, 2021, p. 02). Isso colabora para o rompimento com práticas imediatistas, pragmáticas e mecanizadas. Assim, a definição das ações profissionais e os meios pelos quais serão executados estão relacionados a este complexo e necessário exercício de não desassociar as três dimensões que são pilares para o exercício profissional do assistente social.

Para conhecer de forma ampla a atuação do Serviço Social no IFMG, é fundamental observar questões concernentes à organização institucional e seus impactos para a execução do trabalho do assistente social. Foi possível apurar que $71 \%$ dos campi, possui um setor específico, constituído por equipe multidisciplinar, para operacionalizar as ações previstas na resolução $n^{\circ} 09$ de 03 de julho de 2020, que dispõe sobre a política de assistência estudantil. Nesses campi foram constituídos Núcleos de Apoio ao Educando, ou organização similar, que tem como objetivo desenvolver a política de assistência estudantil.

Recentemente todos os campi foram convocados a adequar os organogramas de acordo com o processo de atualização da Estrutura Organizacional do IFMG, que está em andamento e tem a finalidade de articular a organização administrativa da Reitoria e dos campi. Neste sentido, serão atualizados o Regimento Geral da instituição e os regimentos internos das unidades. (IFMG, 2021d). Isso posto, a assistência estudantil também será reestruturada seguindo as orientações da Reitoria, com base nos fundamentos e princípios da política de assistência estudantil. Um dos exemplos desta reorganização tem ocorrido no campus Ouro Preto, onde iniciamos um processo de transição do setor de Serviço Social, responsável pelos programas da assistência estudantil de caráter socioeconômico, que antes estava vinculado à Diretoria de Relações Empresariais e Comunitárias, para a Diretoria de Ensino. 
Concomitantemente, está ocorrendo a estruturação do Núcleo de Atendimento Integrado ao Estudante (NIAE). Nesse sentido, recentemente, um coletivo constituído por técnicos administrativos, que atuam em diversos setores que atendem diretamente os discente, e representantes do corpo docente, da instituição, têm realizado debates frequentes com a finalidade de organizar este núcleo.

De acordo com os dados obtidos, os campi que possuem Núcleo de Atendimento ao Educando ou uma organização similar contam com diferentes profissionais em sua composição. Conforme previsto no parágrafo único do artigo 66 da resolução ${ }^{\circ} 09$ de 03 de julho de 2020, "a composição da equipe de Assistência Estudantil deve considerar as especificidades de cada unidade e a real demanda pelos profissionais, além das limitações de dimensionamento de pessoal" Além de possuir assistente social em todas as equipes multiprofissionais que atuam na assistência estudantil, através do Núcleo de atendimento ao Educando ou organização similar, foi possível certificar que $90 \%$ conta com psicólogo; 80\% com assistente de aluno; $70 \%$ com pedagogo; $50 \%$ com técnico em administração e intérprete de libras; $40 \%$ com enfermeiro e $10 \%$ com nutricionista.

Ao serem questionados sobre a avaliação que fazem dos recursos humanos e materiais disponíveis para o trabalho no âmbito da assistência estudantil, os assistentes sociais demonstraram maior insatisfação com a disponibilidade de recursos humanos, quando comparado com os recursos materiais. A propósito os profissionais apontaram equipe insuficiente como a segunda dificuldade mais enfrentada no cotidiano de trabalho.

O debate acerca das condições objetivas para a execução do trabalho tem como centralidade a garantia de recursos humanos suficientes para o desenvolvimento das ações de assistência estudantil. É sabido que no IFMG não há disponibilidade de ao menos um assistente social alocado em cada campus existente. Além disso, ao comparar os campi que possuem assistente social em sua equipe técnica, identificamos uma desproporcionalidade quando confrontamos o principal indicador de demandas para o Serviço Social, que se trata do número de alunos matriculados. Portanto, independente do volume de demanda existente, esses campi possuem apenas um assistente social.

Esta realidade se estende a outras categorias profissionais. Isso contribui para que as equipes multiprofissionais, conforme prevê a política de assistência estudantil, apresentem 
diferentes composições. Esta ausência de parâmetros para definir e distribuir os profissionais, no âmbito dos Institutos Federais é, segundo Prada (2019, p.32) uma característica institucional. Pois, "a competência de tal decisão fica a cargo do gestor, do Conselho Nacional das Instituições da Rede Federal de Educação Profissional, Científica e Tecnológica (CONIF) e do Ministério da Educação (MEC)." Desse modo, as deliberações da gestão nem sempre correspondem às prioridades identificadas e definidas na esfera local. Esta divergência entre o que é prioridade e a decisão tomada, tende a se intensificar em contextos de retração de investimentos em políticas educacionais.

Apesar de apontar dificuldades relacionadas aos recursos humanos disponíveis, com ênfase na insuficiência da equipe existente para atuar especificamente na assistência estudantil, um número expressivo dos assistentes sociais entrevistados demonstraram uma avaliação positiva sobre a articulação com demais profissionais que atuam em outros setores existentes nos campi.

Apesar deste número considerável de assistentes sociais avaliarem positivamente a articulação estabelecida com os profissionais inseridos em setores diversos, aproximadamente $86 \%$ considera que servidores, tanto técnicos administrativos como os docentes, bem como os alunos, desconhecem todas as atribuições e competências dos assistentes sociais que atuam na assistência estudantil. Isso se confirma, pois $100 \%$ dos assistentes sociais afirmaram que as principais demandas apresentadas pelos professores e demais servidores, da instituição, ao Serviço Social está relacionada à concessão dos auxílios socioeconômicos. Essa realidade expressa a persistência de uma compreensão reducionista sobre a assistência estudantil e sobre a atuação do assistente social na política de educação.

A atuação do Serviço Social na educação, conforme Almeida (2003, p. 08) deve ser estruturada em quatro focos centrais: ações que tenham como objetivo garantir o acesso à educação; intervenções com a finalidade de promover a permanência do estudante na instituição; atenção para a qualidade dos serviços prestados e o envolvimento e fortalecimento em ações que asseguram uma gestão democrática e participativa na esfera educacional.

A atuação profissional não se restringe à concessão de auxílios socioeconômicos, pois a dimensão socioeducativa do serviço social propõe intervenções que afetem objetiva e subjetivamente a vida dos usuários. Para que isso se efetive, é fundamental desvelar a realidade 
social a qual os alunos estão inseridos. Essa análise crítica de conjuntura supera as compreensões imediatistas e individualizadas sobre o comportamento dos alunos, permitindo ao assistente social identificar possíveis manifestações da questão social que podem interferir negativamente no desempenho escolar.

Um dos desafios enfrentados pelo assistente social é a alienação que atravessa as relações profissionais estabelecidas. Portanto, o assistente social, em conformidade com os princípios e deveres ético-profissional, tem potencial para contribuir com a desconstrução do pensamento cristalizado e equivocado, que muitos profissionais inseridos na instituição possuem. De acordo com Ângelo (2019, p. 121) é um dever ético do assistente social contribuir "para uma releitura da realidade social do estudante, desvelando as imbricadas expressões da questão social que o afetem, desconstruindo possíveis ideias de que se tratam de questões particulares e individuais dos alunos".

Neste sentido, através da dimensão socioeducativa, a intervenção do assistente social pode ocorrer diretamente com os estudantes, mas também com os demais profissionais que atuam cotidianamente com os discentes, na perspectiva de contribuir para que práticas e visões alienadas, que produzem exclusão educacional, sejam substituídas por uma compreensão crítica da realidade social vivenciada pelo estudante e seus rebatimentos na vida acadêmica. Ângelo (2019, p. 123) menciona que o assistente social precisa desenvolver estratégias, apropriando-se de espaços que possibilitam articulações com os demais profissionais que lidam diretamente com os estudantes. Destaca o docente como profissional chave para esta articulação, pois se trata de uma figura presente no cotidiano do estudante e fundamental para contribuir com o acesso amplo a educação, a garantia da permanência e do êxito, desde que suas ideologias e visão de mundo colaborem para a inclusão escolar. Nesse sentido, a atuação do professor vai além dos conteúdos acadêmicos. É preciso estar atento para identificar que diversas questões podem impactar na vida escolar do discente. Portanto, faz-se necessário superar visões imediatistas e romper com estereótipos e padrões que não correspondem à realidade vivenciada pelos estudantes.

Outras articulações imprescindíveis extrapolam o ambiente institucional interno. 100\% dos assistentes sociais, que participaram da pesquisa, afirmaram articular com profissionais que atuam em diversas políticas setoriais com a finalidade de realizar encaminhamentos; estudos de 
caso; obter informações sobre os serviços prestados e divulgar as ações desenvolvidas pela assistência estudantil. Isso se faz necessário, uma vez que o aluno e seu grupo familiar circulam por diversos serviços e políticas públicas e devem ser compreendidos em sua totalidade. Uma intervenção ampliada supera o foco na concessão dos auxílios e considera aspectos dos estudantes para além da demanda financeira explícita, que apesar de não ser considerada menos importante, também não é a única.

As articulações com profissionais vinculados ao IFMG ou que atuam em outras políticas públicas e instituições, revelam a necessidade de uma série de ações que devem ser apropriadas e aprimoradas para contribuir com a estruturação do acompanhamento educacional e sociofamiliar. Compreendido neste estudo como uma forma de contribuir para a qualidade do processo formativo do aluno, esta política deve viabilizar o acesso a seus direitos sociais, através de um conjunto de ações voltadas à atenção social a partir da observação da existência de riscos pessoais e sociais que podem ser submetidos. A resolução $n^{\circ} 09$ de 03 de julho de 2020, que estabelece a Política de Assistência Estudantil do IFMG, garante ao acompanhamento educacional e sociofamiliar um caráter institucional, enfatizando sua necessidade. Contudo, no âmbito da execução deste acompanhamento é possível observar ações pontuais, por vezes fragmentadas e que não dispõem de orientações técnicas que tenham como finalidade contribuir para organizar, estruturar e operacionalizar esta competência. Sendo assim, ao serem questionados sobre a importância da realização do acompanhamento educacional e sociofamiliar e sobre como avaliam a necessidade da criação de um instrumental que disponha de orientações técnicas para respaldar esta atuação profissional, todos os assistentes sociais afirmaram a importância deste acompanhamento e das orientações técnicas para nortear a execução do trabalho. Apesar de todos compreenderem o acompanhamento educacional e sociofamiliar como necessário, $79 \%$ dos assistentes sociais afirmam que existem limitações institucionais para a execução desta intervenção. É possível que esses entraves estejam relacionados às principais dificuldades que eles apontaram enfrentar no cotidiano de trabalho, conforme quadro 1 .

No âmbito do IFMG, o acompanhamento educacional e sociofamiliar, apesar de previsto na política de assistência estudantil e reconhecido como necessário, não é uma prática consolidada. Trata-se de garantir o acompanhamento proposto enquanto um processo de trabalho do assistente social, que dispõe de estratégias e técnicas para elaborar respostas às 
demandas identificadas. Para isso, o profissional requer orientações e metodologias que não se caracterizem como algo etapista, linear e engessado. Refere-se a uma estrutura metodológica constituída por um agrupamento de ações demarcadas por princípios e diretrizes que asseguram uma orientação política à intervenção profissional.

\section{Quadro 1: dificuldades identificadas}

\begin{tabular}{|l|c|}
\hline \multicolumn{1}{|c|}{ Dificuldade } & $\%$ \\
\hline Equipe insuficiente & 64,3 \\
\hline Recursos materiais insuficiente & 14,3 \\
\hline Estrutura física inadequada & 50 \\
\hline $\begin{array}{l}\text { Dificuldade de articulação com os demais setores } \\
\text { existentes no próprio campus }\end{array}$ & 28,6 \\
\hline $\begin{array}{l}\text { Dificuldade de articulação com profissionais que atuam } \\
\text { em outras políticas públicas e/ou instituições }\end{array}$ & 21,4 \\
\hline Ausência de um plano de ação sistematizado & 78,6 \\
\hline $\begin{array}{l}\text { Inexistência de um fluxo de trabalho } \\
\text { Entendimento equivocado, por parte de outros } \\
\text { Profissionais, sobre as atribuições do assistente social }\end{array}$ & 57,1 \\
\hline $\begin{array}{l}\text { Demais profissionais desconhecem a política de } \\
\text { assistência estudantil do IFMG }\end{array}$ & 57,1 \\
\hline $\begin{array}{l}\text { Cobranças para executar competências que não cabe ao } \\
\text { assistente social } \\
\text { assistência estudantil }\end{array}$ & 50 \\
\hline Atuar para além dos processos seletivos para os & 21,4 \\
\hline
\end{tabular}

Fonte: dados da pesquisa, 2021.

Nesse sentido, um estudo que se proponha a contribuir para a execução do acompanhamento educacional e sociofamiliar dos estudantes inseridos no programa de assistência estudantil do IFMG, possibilitará um processo de trabalho mais qualificado para os assistentes sociais e consequentemente contribuirá, de forma efetiva, para ampliar as condições de permanência dos estudantes inseridos no Programa de Assistência estudantil. 


\section{CONSIDERAÇÕES FINAIS:}

A pesquisa realizada revela características que constituem a trajetória construída pelos assistentes sociais no IFMG. É possível, a partir dos dados obtidos, identificar os processos de trabalho desenvolvidos e sua relação com a busca pela consolidação do Serviço Social neste espaço sócio ocupacional. Trata-se de um movimento que envolve impasses e desafios, mas também propostas e construção de possibilidades.

Ao avaliar as intervenções dos assistentes sociais é imprescindível considerar as marcas provocadas pelo contexto contraditório ao qual estão inseridos, consequência da política neoliberal que provoca a retração do papel do Estado no que se refere ao investimento em políticas públicas. Portanto, são apresentadas ao profissional expressivas demandas e os meios para atendê-las efetivamente tornam-se cada vez mais escassos. Os cortes no orçamento destinado à instituição impacta na qualidade dos serviços prestados, pois inviabiliza a ampliação da concessão dos auxílios financeiros aos alunos, interfere na possibilidade de ampliação do quadro de recursos humanos, impossibilita a oferta de ações de capacitação para os servidores, prejudica a melhoria e ampliação dos recursos materiais existentes, entre outras ações fundamentais para garantir o funcionamento adequado da instituição.

Deste modo, sem fomentar um posicionamento messiânico da profissão, mas considerando os princípios estabelecidos no Código de Ética Profissional, mesmo diante das adversidades, cabe ao assistente social desvelar e enfrentar as manifestações da questão social que atravessam a realidade vivenciada pelos estudantes e provocam impactos em sua vida escolar.

O assistente social, assim como os demais profissionais que atuam na educação, são imprescindíveis para fortalecer o processo de ensino e aprendizagem a partir de ações que colaborem para além do ingresso, mas também para permanência e êxito do aluno. Ao Serviço Social, profissão que tem como objeto de intervenção a questão social cabe, a partir da visão ampla e crítica que possui da política de educação, contribuir para propagar e desenvolver a assistência estudantil como uma política que supera as ações vinculadas a transferência de renda. Neste sentido, é fundamental uma leitura crítica da conjuntura institucional para compreender as correlações de forças existentes e se posicionar a fim de delimitar suas 
competências e atribuições, bem como apontar a importância de um trabalho coletivo na perspectiva de promover o acesso e ampliação dos direitos dos estudantes.

O processo de consolidação do Serviço Social, no âmbito da educação, enquanto uma profissão que não restringe suas atividades à concessão de auxílios financeiros exige dos assistentes sociais refletir sobre a prática profissional no sentido de organizá-la para dar visibilidade a outras ações que executa. Nesse sentido, o acompanhamento educacional e sócio familiar estabelecido na Política de Assistência Estudantil do IFMG deve ser idealizado e sistematizado como destaque da prática do assistente social. Pois, as ações que o constituem proporciona uma atuação profissional abrangente que ultrapassa o atendimento de demandas imediatistas. Sendo assim, dispor de orientações técnicas para a execução do acompanhamento educacional e sócio familiar é uma demanda dos assistentes sociais, que atuam no IFMG, para que a partir de diretrizes metodológicas, respaldadas em um viés teórico-crítico, aprimorem o seu trabalho e contribuam para a permanência dos estudantes na instituição.

\section{REFERÊNCIAS:}

ABREU, Marina Maciel; CARDOSO, Franci Gomes. Mobilização social e práticas educativas. In: Serviço Social: Direitos Sociais e competências profissionais. P.594 - 608 . Brasília, DF, 2009.

ALMEIDA, Ney Luiz Teixeira. Serviço Social e Política Educacional: um breve balanço dos avanços e desafios desta relação. 2003. Disponível em: http://cress-sc.org.br/wpcontent/uploads/2020/10/Servi\%C3\%A7o-Social-e-pol\%C3\%ADtica-educacional-Um-brevebalan\%C3\%A7o-dos-avan\%C3\%A7os-e-desafios-desta-rela\%C3\%A7\%C3\%A3o.pdf. Acesso em: 18 de jun. 2021.

ANGELO, Williana. Análise sobre a dimensão político-pedagógica do trabalho do assistente social na inter-relação com os docentes: uma reflexão. In: DUARTE, Amanda Machado dos Santos; Wildiana Nayara Felício Silva; DANTAS, Maraia Conceição Borges; BRANT, Nathália Lopes Caldeira; DAROS, Michelli Aparecida; (Org.). Serviço Social educação profissional e tecnológica. São Paulo, Cortez, 2019.

CARTAXO, Ana Maria Baima; MANFROI, Vania Maria; SANTOS, Maria Teresa. Formação continuada: implicações e possibilidades no exercício profissional do assistente social. R. Katálysis, Florianópolis, v. 15, n. 2, p. 239-253, jul./dez. 2012.

CFESS. Código de Ética do/a Assistente Social \& Lei 8.666/93 de regulamentação da profissão. 10ª edição. Brasília: CFESS, 2012. 
Esclarecimento sobre a implantação da jornada de $\mathbf{3 0}$ horas para Assistentes Sociais sem redução salarial - CFESS. Serv. Soc. Soc., São Paulo, n. 105, p. 185-193, jan./mar. 2011

Subsídios para a atuação de assistentes sociais na política de educação. Série: Trabalho e projeto profissional nas políticas sociais. Brasília, 2014.

Lei federal é pra cumprir: 30h semanais para assistentes sociais. CFESS Manifesta, de 30 de agosto de 2011. Disponível em: http://www.cfess.org.br/arquivos/cfessmanifesta2011_luta30h_site.pdf. Acesso em: 19 mai. 2021.

BRASIL. Lei n. 11.892 de 29, de dezembro de 2008. Institui a Rede Federal de Educação Profissional, Científica e Tecnológica, cria os Institutos Federais de Educação, Ciência e Tecnologia, e dá outras providências. Brasília, 2008. Disponível em: http://www.planalto.gov.br/ccivil 03/ ato2007-2010/2008/lei/l11892.htm. Acesso em: 14 mai. 2021.

Decreto n. 7.234, de 19 de julho de 2010. Plano Nacional de Assistência Estudantil. Brasília, DF. Disponível em: http://www.planalto.gov.br/ccivil_03/_ato20072010/2010/decreto/d7234.htm. Acesso em: 14 mai. 2021

Lei n. 11.091, DE 12 DE JANEIRO DE 2005. Plano de Carreira dos Cargos Técnico-Administrativos em Educação, no âmbito das Instituições Federais de Ensino vinculadas ao Ministério da Educação. Brasília, DF. Disponível em: https://www2.camara.leg.br/legin/fed/lei/2005/lei-11091-12-janeiro-2005-535358normaatualizada-pl.pdf. Acesso em: 18 mai. 2021.

GARCIA, Adilson de Campos; DORSA, Arlinda Antero; OLIVEIRA, Edilene Maria; CASTILHO, Maria Augusta. Educação profissional no Brasil: origem e trajetória. Revista Vozes dos Vales: publicações acadêmicas, UFVJM, 2018, N. 13, p. 1 -18. Disponível em: http://site.ufvjm.edu.br/revistamultidisciplinar/files/2018/05/Edilene1502.pdf. Acesso em: 18 mai. 2021.

GARCIA, Maria Lúcia Teixeira; PRADA, Talita. Assistentes Sociais nos institutos Federais de Educação, Ciência e Tecnologia: expansão, dilemas e desafios. In: DUARTE, Amanda Machado dos Santos; Wildiana Nayara Felício Silva; DANTAS, Maraia Conceição Borges; BRANT, Nathália Lopes Caldeira; DAROS, Michelli Aparecida; (Org.). Serviço Social educação profissional e tecnológica. São Paulo, Cortez, 2019.

GUERRA, Yolanda. A Dimensão técnico-operativa do exercício profissional. Disponível em: http://www.ts.ucr.ac.cr/binarios/pela/pl-000563.pdf. Acesso em: 05 de jun. 2021

IFMG. Histórico e missão. Disponível em: https://www.ifmg.edu.br/portal/sobre-oifmg/historico-e-missao. Acesso em 15 mai. 2021a.

Carta aberta. Disponível em: https://www.ifmg.edu.br/portal/noticias/a-redefederal-de-educacao-profissional-cientifica-e-tecnologica-nao-para-e-nao-pode-parar-2. Acesso em 05 de jun. $2021 b$. 
. Portaria no 716 de 07 de outubro de 2010. Dispõe sobre o Regimento Interno do Núcleo de Assistentes Sociais do IFMG. Belo Horizonte, MG. Disponível em: http://www3.ifmg.edu.br/download/PROEX/Regimento\%20NASIFMG.pdf. Acesso em 15 mai. 2021c.

Portaria no 1154 de 11 de dezembro de 2020. Dispõe sobre a normatização do fluxo do processo de criação e/ou alteração de estrutura organizacional e regimento interno pelas unidades no IFMG. Belo Horizonte, MG. Disponível em: file:///C:/Users/natalia.miranda.IFMG/Downloads/PortariaIFMGn1154\%20\%20FluxoProcessoEstruturasRegimentosIFMG.pdf. Acesso em 27de jun. 2021d.

em 20 jun. 2021e.

. NAPNEE. Disponível em: https://www.ifmg.edu.br/portal/ensino/napnee. Acesso

Resolução $\mathrm{n}^{\text {o }} 35$ de 29 de Outubro de 2019. Disponível em: file:///C:/Users/natalia.miranda.IFMG/Downloads/Resolu\%C3\%A7\%C3\%A3o\%20352019\%20(3).pdf . Acesso em 19 mai.2021f.

PACHECO, Eliezer. Fundamentos políticos-pedagógicos dos Institutos Federais: diretrizes para uma educação profissional e tecnológica transformadora. Ed. IFRN. Natal - RN, 2015.

YAZBEK, Maria Carmelita. O significado sócio-histórico da profissão. In: Serviço Social: direitos sociais e competências profissionais. Brasília: CFESS/ABEPSS, 2009. 